\title{
Relationship Between Shift Work and Clustering of the Metabolic Syndrome Diagnostic Components
}

\author{
Yuri Kawabe ${ }^{1}$, Yasuyuki Nakamura ${ }^{1,2}$, Sayuri Kikuchi ${ }^{3}$, Yoshitaka Murakami $^{4}$, Taichiro Tanaka ${ }^{5}$, \\ Toru Takebayashi ${ }^{6}$, Akira Okayama ${ }^{7}$, Katsuyuki Miura ${ }^{2}$, Tomonori Okamura ${ }^{6}$ and Hirotsugu Ueshima ${ }^{2}$ \\ for HIPOP-OHP Research Group
}

\author{
${ }^{1}$ Cardiovascular Epidemiology, Kyoto Women's University, Kyoto, Japan \\ ${ }^{2}$ Departments of Health Science, Shiga University of Medical Science, Otsu, Japan \\ ${ }^{3}$ Department of Community Network and Collaborative Medicine, Kyoto University Hospital, Kyoto, Japan \\ ${ }^{4}$ Departments of Medical Statistics, Shiga University of Medical Science, Otsu, Japan \\ ${ }^{5}$ Department of Environmental and Occupational Health, Faculty of Medicine, Toho University, Tokyo, Japan \\ ${ }^{6}$ Department of Preventive Medicine and Public Health, School of Medicine, Keio University, Tokyo, Japan \\ ${ }^{7}$ The First Institute of Health Service, Anti-Tuberculosis Association, Tokyo, Japan
}

\begin{abstract}
Aim: To examine the relationship between the type of work and the number of metabolic syndrome diagnostic components (MetS-DC), as well as the risk of MetS, with adjustment for lifestyle habits in Japanese workers.

Methods: We examined the baseline data from 4,427 participants ( $81.4 \%$ male) aged 19 to 69 years old. The physical activity of each participant was classified according to the International Physical Activity Questionnaire (IPAQ). We defined the four MetS-DC in this study as follows: 1) high blood pressure (BP): systolic $\mathrm{BP} \geq 130 \mathrm{mmHg}$, or diastolic $\mathrm{BP} \geq 85 \mathrm{mmHg}$, or the use of antihypertensive drugs; 2) dyslipidemia: high-density lipoprotein-cholesterol concentration $<40 \mathrm{mg} / \mathrm{dl}$ or triglyceride concentration $\geq 150 \mathrm{mg} / \mathrm{dl}$, or on medication for dyslipidemia; 3) dysglycemia: fasting blood sugar level $\geq 110 \mathrm{mg} / \mathrm{dl}$, or if less than eight hours after meals $\geq 140 \mathrm{mg} / \mathrm{dl}$, or on medication for diabetes mellitus; 4) overweight: a body mass index $\geq 25 \mathrm{~kg} / \mathrm{m}^{2}$. We defined MetS as overweight plus two or more of the MetS-DC.

Results: There were 3,094 subjects in the daytime work group, 73 in the fixed nighttime work group, 1,017 in the shift work group and 243 in the day-to-night work group. The Poisson regression analysis revealed that fixed nighttime (regression coefficient $[b]=-0.233, P=0.028$ ) and shift work $(b=0.098, P=0.034)$ independently contributed to the number of MetS-DC, compared to daytime work. The multivariate logistic analysis not including sleep hours in the model showed that shift work was positively related to MetS (odd ratio $=1.47, P<0.01$ ).

Conclusion: Shift work were significantly associated with the number of MetS-DC, and was related to risk of MetS compared to daytime work.
\end{abstract}

J Atheroscler Thromb, 2014; 21:703-711.

Key words: Shift work, Metabolic syndrome, Diagnostic components, International Physical Activity Questionnaire, Smoking, Alcohol

Address for correspondence: Yasuyuki Nakamura, Cardiovascular Epidemiology, Kyoto Women's University, 35 Imakumano Kitahiyoshi-cho, Higashiyama-ku, Kyoto 605-8501, Japan

E-mail: nakamury@kyoto-wu.ac.jp

Received: October 25, 2013

Accepted for publication: January 24, 2014

\section{Introduction}

The work environment is known to exert both beneficial and negative health effects among the working population ${ }^{1-8)}$. Shift work can be defined as employment in any work schedule that is not a regular 
daytime schedule (that is, approximately 0900 to $1700)^{3)}$. The full spectrum of shift work comprises regular evening or night schedules, rotating shifts, split shifts, on-call or casual shifts, 24-hour shifts, irregular schedules and other non-day schedules. A flexible work patterns remain a necessary component for a dynamic, diversified industrial economy ${ }^{4)}$. However, shift work has long been known to disrupt circadian rhythm, sleep and work-life balance; a higher incidence of coronary heart disease ${ }^{5)}$, metabolic syndrome $^{6}$, as well as mental and behavioral disorders ${ }^{7)}$ and sleep disturbances ${ }^{8)}$, has also been described among shift workers.

The prevalence of people with metabolic syndrome diagnostic components (MetS-DC) is increasing in Japan, as well as globally. MetS-DC such as high blood pressure (BP), dyslipidemia, dysglycemia and being overweight/obese tend to cluster together and are closely related to insulin resistance ${ }^{9-12)}$. The clustering of MetS-DC is known as metabolic syndrome (MetS), and is thought to be related to lifestyle habits, including nutrient intake, physical activity, smoking and alcohol consumption ${ }^{11-14)}$. Numerous studies have shown that separate components of the MetS-DC are associated with a higher risk of coronary heart disease and stroke, and that an increase in the number of MetS-DC increases the incidence of cardiovascular disease (CVD) events following myocardial infarction ${ }^{15-17)}$. Therefore, preventing the development of MetS-DC is more important than dichotomizing people into two groups, namely those with and without MetS, in order to prevent the development of MetS. No previous study has examined the associations of shift work with MetS-DC. In addition, there have been very few studies that have examined the relationships between shift work and MetS or MetSDC that took into consideration the various factors associated with shift work that might lead to MetS.

\section{Aim}

The aim of the present study was to cross-sectionally examine the relationship between the type of work and MetS, as well as the number of MetS-DC, with adjustment for lifestyle habits in Japanese workers. Furthermore, we wanted to evaluate the roles of being overweight and having sleep impairment as mediators of the increased development of MetS or MetS-DC by shift workers.

\section{Methods}

\section{Participants}

We analyzed the baseline data from the high-risk and population strategy for occupational health promotion (HIPOP-OHP) study ${ }^{18-21)}$. In brief, the HIPOP-OHP was an interventional survey to establish a methodology for reducing CVD risk factors in the workplace. This study population consisted of fulltime workers at 12 large companies throughout Japan. Each company had 500-1000 employees. Researchers collected data regarding CVD risk factors and lifestyle habits ${ }^{18-21)}$. This study was carried out as part of the management of safety and health, with the approval of the Safety Hygiene Committee at each company. Approval for the study was obtained from the Institutional Review Board of Shiga University of Medical Science for Ethical Issues (No. 10-16). From 1999 to 2000, baseline data were collected from 7,346 male and female workers aged 19-69 years old. The present study examined the baseline data from 4,427 participants (3,604 males and 823 females), aged 19-69 years old (mean $\pm S D, 41.9 \pm 9.4$ years) who underwent a physical examination, a lifestyle survey and a blood chemical examination.

\section{Data Collection and Standardization}

Physical and laboratory data were standardized according to the manual of the HIPOP-OHP research group ${ }^{18)}$. Briefly, after $5 \mathrm{~min}$ of silent rest measured by an hourglass, the blood pressure (BP) was measured twice for each participant using an automatic sphygmomanometer (BP-103ilI; Omron Colin, Tokyo, Japan) at each company, and the mean value was recorded. To measure the lipid levels in each participant, the company established a contract with a clinical laboratory; the blood testing was standardized through the US Cholesterol Reference Method Laboratory Network (CRMLN) ${ }^{22)}$. The non-HDL-cholesterol (non-HDL) level was calculated by subtracting HDL from the total cholesterol concentration ${ }^{23)}$. The BMI was calculated as the weight (in $\mathrm{kg}$ ) divided by the height squared $\left(\mathrm{m}^{2}\right)$. Information on the shift work schedule at the baseline (daytime work, fixed nighttime, [rotating] shift or day-to-night work) and the average overtime work hours per day in the previous one month (seldom, $<1 \mathrm{~h}, 1$ to $<2 \mathrm{~h}, \geq 2 \mathrm{~h}$ ) was obtained from a questionnaire. The sleep duration was investigated using the question, 'How many hours of sleep do you get on an average weekday per night?' in the lifestyle survey. The physical activity of each participant was converted into MET-minutes per week (=MET level $\mathrm{x}$ minutes of activity/day $\mathrm{x}$ days per 
week) according to the International Physical Activity Questionnaire (IPAQ) ${ }^{24)}$, and participants were classified into four classes of physical activity; high $(\geq 3000$ MET-minutes per week), moderate $(<3000$ but $\geq$ 1500 MET-minutes per week), some activity $(<1500$ but $\geq 600$ MET-minutes per week) or sedentary $(<$ 600 MET-minutes per week). The drinking habits for each subject were assessed by a questionnaire common to all companies ${ }^{19)}$. Drinkers were defined as those consuming more than $1 \mathrm{~g}$ of ethanol per day. The average alcohol intake ( $\mathrm{ml}$ ) per day was obtained for each participant ${ }^{19)}$.

We defined four MetS-DC in this study as follows: 1) high BP: systolic BP (SBP) $\geq 130 \mathrm{mmHg}$, or diastolic $\mathrm{BP}(\mathrm{DBP}) \geq 85 \mathrm{mmHg}$ or the use of an antihypertensive drug; we defined dyslipidemia in two ways: 2a) high-density lipoprotein cholesterol (HDL) $<40 \mathrm{mg} / \mathrm{dl}$ for males, or HDL $<50 \mathrm{mg} / \mathrm{dl}$ for females, or triglycerides (TG) $\geq 150 \mathrm{mg} / \mathrm{dl}$ for both sexes, or on medication for dyslipidemia; or $2 \mathrm{~b}$ ) non-HDL $\geq$ $160 \mathrm{mg} / \mathrm{dl}$ for both sexes, or on medication for dyslipidemia (the cutoff level was chosen to be when the prevalence of $2 \mathrm{a}$ and $2 \mathrm{~b}$ were similar) ${ }^{23)}$; 3) dysglycemia: a fasting plasma glucose concentration $\geq 110 \mathrm{mg} /$ $\mathrm{dl}$, or if less than eight hours after meals $\geq 140 \mathrm{mg} / \mathrm{dl}$ ), or on medication for diabetes mellitus ${ }^{17,25,26)}$; 4) overweight: defined as a BMI $\left.\geq 25 \mathrm{~kg} / \mathrm{m}^{2} 27,28\right)$. We defined MetS as overweight plus two or more of the high BP, dyslipidemia or dysglycemia. Although the recent WHO guidelines suggests that a BMI $<23.0 \mathrm{~kg} / \mathrm{m}^{2}$ is healthy for Asians ${ }^{29)}$, we found that the risk of total mortality was lowest in participants with a BMI 23.0$24.9 \mathrm{~kg} / \mathrm{m}^{2}$ in Japan ${ }^{28}$. Thus, we used a cutoff for overweight as a BMI $\geq 25 \mathrm{~kg} / \mathrm{m}^{2}$.

\section{Statistical Analyses}

The chi-square test was used to compare dichotomous variables to see whether there were significant differences among the groups stratified by work type, followed by a post-hoc application of Bonferroni's method comparing the data to those of the daytime work group. A one-way analysis of variance was used to compare the means among the groups, followed by a post-hoc application of Dunnett's test, which compared the data to those of the daytime work group when the $\mathrm{F}$ values showed a significant difference at $P$ $<0.05$.

Associations between the type of work, lifestyle and the number of MetS-DC (defining dyslipidemia as $2 \mathrm{a}$ or $2 \mathrm{~b}$ as above) were analyzed by Poisson regression models, including the age, sex, type of work (nighttime, shift, day-to-night vs. daytime), alcohol consumption (ml/day), IPAQ classification (IPAQ2 to
IPAQ4 vs. IPAQ1), sleep hours, average overtime work hours per day ( $<1 \mathrm{~h}, 1$ to $<2 \mathrm{~h}, \geq 2 \mathrm{~h}$ vs. seldom), smoking status (ex-smoker, current smoker (1-9, 10-19, $\geq 20$ cigarettes per day vs never-smoker); data not shown), and work site (site 1 to 12 , site 1 as a reference). To examine the contribution of being overweight to the associations of the type of work with the number of MetS-DC, the above analysis was performed after stratification by the presence of overweight (BMI $\geq 25 \mathrm{~kg} / \mathrm{m}^{2}$ ), excluding the overweight component from MetS-DC. The relationships between lifestyle traits, including the type of work and MetS, were analyzed by logistic regression models. In the logistic regression, we included potential confounders in the model. First, we defined dyslipidemia as abnormal HDL and triglyceride levels, as stated above. In model 1, we included the sex, age, type of work (nighttime, shift, day-to-night vs. daytime), and site (site 1 to 12 , site 1 as a reference).

In model 2 , in addition to the model 1 covariates, we included the alcohol intake $(\mathrm{ml} /$ day), smoking status (ex-smoker, current smoker (1-9, 10-19, $\geq$ 20 cigarettes per day) vs. never-smoker), average overtime work hours per day ( $<1 \mathrm{~h}, 1$ to $<2 \mathrm{~h}, \geq 2 \mathrm{~h}$ vs. seldom) and IPAQ classification (IPAQ2 to IPAQ4 vs. IPAQ1). In model 3, in addition to the model 2 covariates, we included the sleep hours. In model 4, the model 3 analysis was performed by defining dyslipidemia as a non-HDL level $\geq 160 \mathrm{mg} / \mathrm{dl}$ or on medication for dyslipidemia. A Poisson regression analysis and model 4 logistic regression analysis were also performed after stratifying by sex. All statistical tests were two-sided, and a value of $P<0.05$ was considered to be statistically significant. All analyses were carried out using the SAS version 9.4 software program for Windows (SAS Institute, Cary, NC, USA).

\section{Results}

Among the 4,427 participants, 3,094 were in the daytime work group, 73 were in the fixed nighttime work group, 1,017 were in the shift work group and 243 were in the day-to-night work group. Among these participants, those who had 0 to 4 MetS-DC accounted for 2,184, 1,255, 674, 262 and 52 people, respectively, in the Poisson distribution. The characteristics of the participants by group according to the type of work are shown in Table $\mathbf{1}$. There were fewer females among the non-daytime work groups. The mean age, SBP, DBP, alcohol consumption per day and the percentages of subjects with a high BP, dyslipidemia, dysglycemia and IPAQ4 were higher in the fixed nighttime work group compared to the daytime 
Table 1. The Characteristics of the Participants Divided into Groups According to the Type of Work

\begin{tabular}{|c|c|c|c|c|c|c|c|}
\hline Type of Work & Daytime & Fixed nighttime & Shift & Day-to-night & $P$ & Total & Range \\
\hline Number of people & 3,094 & 73 & 1,017 & 243 & & 4,427 & \\
\hline Female (\%) & 23.0 & $1.4^{*}$ & $7.5^{* *}$ & $13.1^{* *}$ & $<0.001$ & 18.6 & \\
\hline SBP (mmHg) & $116.7 \pm 16.6$ & $128.2 \pm 17.4^{*}$ & $120.0 \pm 16.2^{* *}$ & $120.2 \pm 17.5^{* *}$ & $<0.001$ & $117.8 \pm 16.8$ & $74.5-19705$ \\
\hline Dyslipidemia (\%) & 24.9 & $56.2^{*}$ & $29.0^{*}$ & 30.5 & $<0.001$ & 26.7 & \\
\hline High non-HDL (\%) & 27.4 & 42.5 & 26.8 & 30.0 & 0.742 & 27.7 & \\
\hline Dysglycemia (\%) & 8.0 & $16.4^{*}$ & 6.9 & 7.9 & 0.032 & 7.8 & \\
\hline Overweight (\%) & 20.1 & 20.6 & $26.2^{* *}$ & 24.7 & $<0.001$ & 21.8 & \\
\hline IPAQ1 (\%) & 35.1 & 46.6 & $45.7^{*}$ & 40.7 & $<0.001$ & 38.1 & \\
\hline Sleep (h) & $6.40 \pm 0.85$ & $6.47 \pm 1.09$ & $6.46 \pm 1.07$ & $6.15 \pm 1.06^{* *}$ & $<0.001$ & $6.41 \pm 0.95$ & $3-15$ \\
\hline Overwork $\geq 2$ h/d (\%) & 34.0 & $9.6^{* *}$ & $21.3^{* *}$ & $47.7 * *$ & $<0.001$ & 31.5 & \\
\hline $\operatorname{BMI}\left(\mathrm{kg} / \mathrm{m}^{2}\right)$ & $22.7 \pm 3.06$ & $22.8 \pm 2.91$ & $23.3 \pm 3.37^{* *}$ & $23.4 \pm 3.30^{* *}$ & $<0.001$ & $22.9 \pm 3.17$ & $14.5-47.6$ \\
\hline Alcohol (ml/d) & $20.7 \pm 29.9$ & $29 \pm 40.2$ & $22.4 \pm 35.2$ & $17.1 \pm 26$ & 0.003 & $21.0 \pm 31.3$ & $0-250$ \\
\hline
\end{tabular}

The values are shown as the means \pm SD, or $\%$. The characteristics of participants divided by group according to the type of work in 4,427 Japanese males and females evaluated in 1999-2000 are shown. The chi-square test was used to compare dichotomous variables to see whether there were significant differences among the groups stratified by the type of work, followed by a post-hoc application of Bonferroni's method. A one-way analysis of variance was used to compare the means among the groups, followed by a post-hoc application of Dunnett's test when the F value showed a significant difference at $p<0.05$. We defined four MetS-DC in this study as follows: 1) high blood pressure (BP): systolic BP (SBP) $\geq 130 \mathrm{mmHg}$, or $\mathrm{DBP} \geq 85 \mathrm{mmHg}$, or the use of an antihypertensive drug; 2) dyslipidemia: HDL $<40 \mathrm{mg} / \mathrm{dl}$ for men, or HDL $<50 \mathrm{mg} / \mathrm{dl}$ for women, or TG $\geq$ $150 \mathrm{mg} / \mathrm{dl}$ for both genders, or on medication for dyslipidemia; 3) dysglycemia: fasting blood sugar concentration $\geq 110 \mathrm{mg} / \mathrm{dl}$, or if less than eight hours after meals $\geq 140 \mathrm{mg} / \mathrm{dl}$ ), or on medication for diabetes mellitus; 4) overweight: defined as a BMI $\geq 25 \mathrm{~kg} / \mathrm{m}^{2}$. We defined metabolic syndrome as being overweight plus two or more of high BP, dyslipidemia or dysglycemia. The non-HDL-cholesterol (non-HDL) level was calculated by subtracting the HDL from the total cholesterol concentration. A high non-HDL level was defined as non-HDL $\geq 160 \mathrm{mg} / \mathrm{dl}$ for both genders. ${ }^{*} P<0.05,{ }^{* *} P<0.01$ compared to daytime work. $\mathrm{SBP}=$ systolic blood pressure, $\mathrm{DBP}=$ diastolic blood pressure, Met $S=$ metabolic syndrome, $\mathrm{BMI}=$ body mass index, IPAQ = International Physical Activity Questionnaire classification .

work group. Compared to the daytime work group, the mean age in the shift work group was lower; the mean SBP, BMI and the percentages of dyslipidemia, being overweight, the IPAQ1, IPAQ4, current smoking and MetS were higher. Compared to the daytime work group, the mean age in the day-to-night work group was lower; the mean SBP, BMI and the percentages of subjects who were overweight and current smokers were higher. The mean sleep hours in the day-to-night work group was less than that in the daytime work group.

The results of the Poisson regression analysis are shown in Table 2. When we defined dyslipidemia as a lower HDL or a higher triglycerides, the independent factors that positively contributed to the number of MetS-DC were the age (regression coefficient $[\mathrm{b} 1]=0.025, P<0.001)$, being male (b1 $=0.446, P<$ $0.001)$, shift work vs daytime work $(\mathrm{b} 1=0.098$, $P=0.034)$ and alcohol consumption $(\mathrm{ml} / \mathrm{d})$ (b1=0.002, $P=0.003)$. Fixed nighttime vs. daytime work $(\mathrm{b} 1=-0.233, P=0.028)$, IPAQ4 vs IPAQ1 (b1 $=-0.366, P=0.032)$ and sleep $(h)(b 1=-0.078$, $P<0.001)$ significantly inversely contributed to the number of MetS-DC. When dyslipidemia was defined as a higher non-HDL, the positive association of shift work vs. daytime work, and the positive association with alcohol, and the inverse association of the IPAQ4 vs IPAQ1 with the number of MetS-DC (b2 and P2) lost their statistical significance. The analysis in just males yielded similar results, but not the analysis focused on women, probably due to the smaller number of female participants (data not shown).

The results of the analysis stratified by the presence of overweight (BMI $\geq 25 \mathrm{~kg} / \mathrm{m}^{2}$ ) by Poisson regression models on the associations between the type of work, lifestyle traits and the number of MetS-DC (excluding overweight) are shown in Table 3. Significant positive associations were found for day-to-night 
Table 2. The Independent Factors That Contributed to the Number of Metabolic Syndrome Diagnostic Components: Results of Poisson Regression Analysis

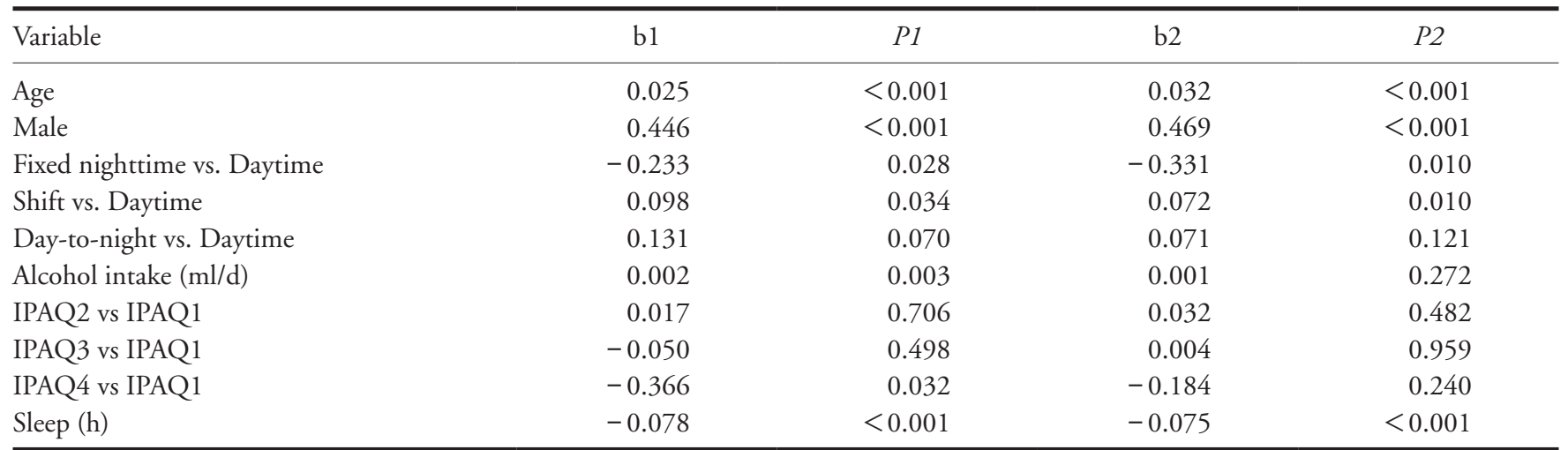

The results of analysis by Poisson regression models on associations between the type of work, lifestyle traits and the number of MetS-DC are shown. The covariates included were age, sex, work site (site 2 to 12, vs site 1), work type (nighttime, shift, day-to-night vs. daytime), alcohol consumption (ml/day), IPAQ classification (IPAQ2 to IPAQ4 vs. IPAQ1), sleep hours, average overtime work hours per day ( $<1 \mathrm{~h}, 1$ to $<2 \mathrm{~h}, \geq 2 \mathrm{~h}$ vs. seldom) and smoking status (ex-smoker, current smoker (1-9, 10-19, $\geq 20$ cigarettes per day) vs. never-smoker; data not shown). b1 and P1 are the regression coefficients and $P$ values when dyslipidemia was defined as high-density lipoprotein cholesterol (HDL) $<40 \mathrm{mg} / \mathrm{dl}$ for men, or HDL $<50 \mathrm{mg} / \mathrm{dl}$ for women, or triglycerides (TG) $\geq 150 \mathrm{mg} / \mathrm{dl}$ for both genders, or on medication for dyslipidemia; b2 and P2 are the regression coefficients and $P$ values when dyslipidemia was defined as non-HDL $\geq 160 \mathrm{mg} / \mathrm{dl}$ for both genders, or on medication for dyslipidemia. IPAQ=International Physical Activity, MetS-DC $=$ metabolic syndrome diagnostic components.

Table 3. Independent Factors that Contributed to the Number of Metabolic Syndrome Diagnostic Components Stratified by Overweight: Results of the Poisson Regression Analysis

\begin{tabular}{lcccccc}
\hline & \multicolumn{2}{c}{ BMI $<25 \mathrm{~kg} / \mathrm{m}^{2}$} & $(N=3,454)$ & & \multicolumn{2}{c}{ BMI $\geq 25 \mathrm{~kg} / \mathrm{m}^{2}(N=973)$} \\
\cline { 2 - 3 } \cline { 5 - 6 } Variable & $\mathrm{b} 1$ & 0.040 & $<1$ & & $\mathrm{~b} 1$ & P1 \\
\hline Age & 0.428 & $<0.001$ & & 0.011 & 0.005 \\
Male & -0.082 & 0.001 & & 0.245 & 0.042 \\
Fixed nighttime vs. Daytime & 0.062 & 0.382 & & 0.037 & 0.881 \\
Shift vs. Daytime & 0.242 & 0.025 & & 0.097 & 0.256 \\
Day-to-night vs. Daytime & & & & & 0.021 & 0.880 \\
\hline
\end{tabular}

The results of the analysis stratified by the presence of overweight $\left(\mathrm{BMI} \geq 25 \mathrm{~kg} / \mathrm{m}^{2}\right)$ by Poisson the regression models on the associations between the type of work, lifestyle traits and the number of MetS-DC (excluding overweight) are shown. The covariates included were the same as in Table 2. Here, we defined dyslipidemia as high-density lipoprotein cholesterol (HDL) $<40 \mathrm{mg} / \mathrm{dl}$ for men, or HDL $<50 \mathrm{mg} / \mathrm{dl}$ for women, or triglycerides (TG) $\geq 150 \mathrm{mg} / \mathrm{dl}$ for genders, or on medication for dyslipidemia. $\mathrm{BMI}=$ body mass index, MetS-DC= metabolic syndrome diagnostic components.

vs. daytime work with the number of MetS-DC in participants who were not overweight $(\mathrm{b} 1=0.242$, $P 1=0.025)$. No associations were found between any type of work and the number of MetS-DC in participants who were overweight, probably due to the smaller number of participants who were overweight.

The results of a logistic regression analysis of the relationship between the type of work, lifestyle and MetS are shown in Table 4. In model 1, the independent factors that were significantly and positively related to $\mathrm{Met} S$ were age (odds ratio $[\mathrm{OR}]=1.02[95 \%$ confidence intervals [1.01-1.04], $P<0.01)$, being male $(\mathrm{OR}=2.35$ [1.56-3.55], $P<0.01)$ and shift vs. daytime work $(\mathrm{OR}=1.47[1.05-2.05], P<0.01)$. In model 2, the independent factors that were significantly positively related to MetS were age $(\mathrm{OR}=1.02$ [1.01-1.04], $P<0.01)$, being male $(\mathrm{OR}=2.45$ [1.594.00], $P<0.01)$ and shift vs. daytime work $(\mathrm{OR}=1.42$ [1.01-1.99], $P<0.05)$. The addition of the sleep duration to model 2 covariates resulted in a marginal disappearance of the statistical significance of shift vs. daytime work in model 3 . When we defined dyslipidemia as non-HDL $\geq 160 \mathrm{mg} / \mathrm{dl}$, or as subjects who were on medication for dyslipidemia in model 4 , the independent factors that were significantly positively related to $\mathrm{MetS}$ were age $(\mathrm{OR}=1.04$ [1.03-1.06], $P<$ $0.01)$, being male $(\mathrm{OR}=2.56$ [1.66-3.95], $P<0.01)$ and shift vs. daytime work $(\mathrm{OR}=1.47$ [1.06-2.04], $P$ 
Table 4. Independent Factors Associated with Metabolic Syndrome: Results of the Logistic Regression Analysis

\begin{tabular}{|c|c|c|c|c|c|c|c|c|}
\hline Variables & \multicolumn{2}{|c|}{ Model 1} & \multicolumn{2}{|c|}{ Model 2} & \multicolumn{2}{|c|}{ Model 3} & \multicolumn{2}{|c|}{ Model 4} \\
\hline Age (years) & $1.02^{* *}$ & $1.01-1.04$ & $1.02^{* *}$ & $1.01-1.04$ & $1.02^{* *}$ & $1.01-1.04$ & $1.04^{* *}$ & $1.03-1.06$ \\
\hline Male & $2.35^{* *}$ & $1.56-3.55$ & $2.45^{* *}$ & $1.55-3.88$ & $2.52 * *$ & $1.59-4.00$ & $2.56^{* *}$ & $1.66-3.95$ \\
\hline Fixed nighttime vs. Daytime & 0.46 & $0.18-1.14$ & 0.44 & $0.18-1.11$ & 0.42 & $0.17-1.07$ & 0.63 & $0.27-1.47$ \\
\hline Shift vs. Daytime & $1.47^{* *}$ & $1.05-2.05$ & $1.42 *$ & $1.01-1.99$ & 1.51 & $0.998-1.97$ & $1.47^{*}$ & $1.06-2.04$ \\
\hline Ex-smoker vs. Never smoker & & & 0.93 & $0.64-1.37$ & 0.94 & $0.64-1.38$ & 1.17 & $0.81-1.70$ \\
\hline Current smoker (1-9 cig/d) vs. Never & & & 1.03 & $0.43-2.56$ & 1.04 & $0.44-2.50$ & 1.09 & $0.45-2.63$ \\
\hline Current smoker $(10-19 \mathrm{cig} / \mathrm{d})$ vs. Never & & & 0.80 & $0.51-1.25$ & 0.81 & $0.51-1.27$ & 1.02 & $0.66-1.58$ \\
\hline Current smoker ( $\geq 20 \mathrm{cig} / \mathrm{d}$ ) vs. Never & & & 1.04 & $0.75-1.45$ & 1.04 & $0.75-1.46$ & 1.09 & $0.78-1.53$ \\
\hline IPAQ2 vs IPAQ1 & & & 1.08 & $0.78-1.50$ & 1.09 & $0.78-1.51$ & 1.06 & $0.77-1.47$ \\
\hline
\end{tabular}

The odds ratios (OR) and 95\% confidence intervals (95\% CI) of the analyses by logistic regression models on the relationships between the type of work, lifestyle traits and metabolic syndrome are shown. First, we defined dyslipidemia as high-density lipoprotein cholesterol (HDL) $<40 \mathrm{mg} / \mathrm{dl}$ for men, or HDL $<50 \mathrm{mg} / \mathrm{dl}$ for women, or triglycerides (TG) $\geq 150 \mathrm{mg} / \mathrm{dl}$ for both genders, or on medication for dyslipidemia. In model 1 , we included sex, age, the type of work (nighttime, shift, day-to-night vs. daytime), and site (site 1 to 12 , site 1 as a reference). In model 2 , in addition to the model 1 covariates, we included the alcohol intake (ml/day), smoking status (ex-smoker, current smoker (1-9, 10-19, $\geq 20$ cigarettes per day) vs. never-smoker), the average overtime work hours per day ( $<1 \mathrm{~h}, 1$ to $<2 \mathrm{~h}, \geq 2 \mathrm{~h}$ vs. seldom) and the IPAQ classification (IPAQ2 to IPAQ 4 vs IPAQ1). In model 3, in addition to the model 2 covariates, we included the sleep hours. In model 4, the model 3 analysis was performed by defining dyslipidemia as non-HDL $\geq 160 \mathrm{mg} / \mathrm{dl}$, or on medication for dyslipidemia for both genders. ${ }^{*} P<0.05$, ${ }^{* *} P<0.01$. IPAQ $=$ International Physical Activity Questionnaire classification.

$<0.01)$. The sleep duration was inversely associated with MetS $(\mathrm{OR}=0.85$ [0.74-0.97], $P<0.01)$. The model 4 analysis of only male subjects yielded similar results, but not in only women (data not shown).

\section{Discussion}

In the present study, when we defined dyslipidemia as having a lower HDL and a higher triglyceride level, we found that shift work was significantly and positively associated with, and fixed nighttime work was significantly and inversely associated with, the number of MetS-DC compared to daytime work, independent of confounding factors, using a Poisson regression analysis. When we defined dyslipidemia as having a higher non-HDL level, the inverse association of fixed nighttime vs. daytime work with the number of MetS-DC remained significant, but the positive association of shift vs. daytime work lost its statistical significance. By a logistic regression analysis, we found that shift work was significantly and positively related to the risk of MetS compared to daytime work when we defined dyslipidemia as having a higher non-HDL level.
Our findings regarding shift work are consistent with those of previous studies ${ }^{30-34)}$. A higher risk of having more MetS-DC was observed through a range of different occupations, such as police officers, road builders, factory workers and nurses in different countries and areas in cross-sectional studies ${ }^{30-32)}$, as well as in cohort studies ${ }^{33,34)}$. However, there have been conflicting reports on the association of shift work with cardiovascular disease morbidity and mortality in cohort studies ${ }^{5,35-38)}$. A recent meta-analysis by Vyas et al. including 34 studies and more than 2 million people confirmed that shift work was associated with an increased risk of myocardial infarction and stroke ${ }^{39}$.

A higher prevalence of MetS-DC, such as hypertension, dyslipidemia, dysglycemia, or MetS would account for the association of shift work with increased risk cardiovascular morbidity and mortality. Gaining weight, disruption of the circadian rhythm and impairment of sleep associated with shift work have been shown to generate more MetS-DC ${ }^{5-8,40-42)}$. Scheer et al. showed adverse cardiometabolic effects of the circadian misalignment produced by shifting the eating and sleeping time 12 hours out of phase from habitual times, which resulted in systematically 
decreased leptin, increased glucose despite increased insulin, a completely reversed daily cortisol rhythm, an increased mean arterial pressure and reduced sleep efficiency ${ }^{43)}$. The fact that the addition of sleep hours to model covariates in the logistic analysis resulted in the disappearance of the statistical significance of shift vs. daytime work in the present study confirms the importance of sleep impairment as a mediator of the relationship. However, the statistical significance of shift work on the risk of MetS remained even after the inclusion of the sleep hours in the logistic analysis when we defined dyslipidemia as having a higher nonHDL level in the present study. This may imply that other factors besides the sleep hours affected the relationship. The significant positive association of dayto-night vs. daytime work with the number of MetSDC in participants who were not overweight may also imply that factors other than being overweight affect this relationship.

We found that fixed nighttime work was significantly and inversely associated with the number of MetS-DC compared to daytime work using a multivariate Poisson regression analysis. There have been few studies that have examined the effects of fixed nighttime work on health. In their prospective cohort study, Fujino et al. found that fixed nighttime work was not associated with ischemic heart disease compared to daytime work ${ }^{5)}$. Some studies have indicated that adaptation of the circadian rhythm by fixed night workers can be achieved, while this is not possible for rotating-shift workers ${ }^{44,45)}$. However, there have been no studies that have shown any favorable effect of fixed night work on the cardiometabolic risk factors, and an inverse relationship was not noted between fixed night work and MetS by the logistic analysis in the present study. Further studies are needed to reevaluate the relationship.

We found that day-to-night work was significantly associated with the number of MetS-DC using a multivariate Poisson regression analysis in participants who were not overweight. Kobayashi et al. found that longer working hours were significantly associated with the risk of $\mathrm{Met} \mathrm{S}^{46}$. We partially confirmed their results.

Our findings of a significant direct association of alcohol consumption, and the inverse associations of physical activity and sleep duration with MetS-DC, are consistent with previous studies by others and our group $^{2,8,46-48)}$

This is the first study to examine the effect of incorporating a higher non-HDL level as a dyslipidemia component of MetS-DC. When we set the cutoff value of the non-HDL so that the prevalence of dyslipidemia became similar to that derived from the usual criteria, we found that the results of the Poisson and logistic regression analyses using the two different definitions of dyslipidemia were comparable.

In conclusion, shift work was significantly and positively associated with the number of MetS-DC compared to daytime work, independent of confounding factors. Shift work, compared to daytime work, was also significantly related to the risk of MetS.

\section{Acknowledgments}

This study was funded by research grants from the Ministry of Health and Welfare of Japan (H10-12, No. 063, Research on Health Services, Health Sciences Research Grants and H13, No. 010, Medical Frontier Strategy Research, Health Sciences Research Grants), the Ministry of Health, Labor, and Welfare of Japan (H14-15, No. 010, Clinical Research for Evidence-Based Medicine, Health, and Labor Sciences Research Grants), and the Japan Arteriosclerosis Prevention Fund 2004. We thank Toshimi Yoshida, Shiga University of Medical Science, for her excellent clerical support during this research.

The investigators and members of the research group are listed in the appendix of Reference 19.

\section{Conflicts of Interest}

None.

\section{References}

1) Bøggild H, Burr H, Tüchsen F, Jeppesen HJ: Work environment of Danish shift and day workers. Scand J Work Environ Health, 2001; 27: 97-105

2) Frost P, Kolstad HA, Bonde JP: Shift work and the risk of ischemic heart disease- a systematic review of the epidemiologic evidence. Sand J Work Environ Health, 2009; 35: 163-179

3) Williams C: Work-life balance of shift workers. Volume 9. issue 8. Statistics Canada, 2008

4) Hale HB, Williams EW, Smith BN, Melton CE Jr: Neuroendocrine and metabolic response to intermittent night shift work. Aerosp Med, 1971; 42: 156-162

5) Fujino $Y$, Iso $H$, Tamakoshi $A$, Inaba $Y$, Koizumi $A$, Kubo T, Yoshimura T: A prospective cohort study of shift work and risk of ischemic heart disease in Japanese male workers. Am J Epidemiol, 2006; 164: 128-135

6) Karlsson B, Knutsson A, Lindahl B: Is there an association between shift work and having a metabolic syndrome? Results from a population based study of 27,485 people. Occup Environ Med, 2001; 58: 747-752

7) Woo JM, Postolache TT: The impact of work environment on mood disorders and suicide. Evidence and implications. Int J Disabil Hum Dev, 2008; 7: 185-200 
8) Ohayon MM, Lemoine P, Arnaud-Briant V, Dreyfus M: Prevalence and consequences of sleep disorders in a shift worker population. J Phychosom Res, 2002; 53: 577-583

9) Bhatt DL, Steg PG, Ohman EM, Hirsch AT, Ikeda Y, Mas JL, Goto S, Liau CS, Richard AJ, Röther J, Wilson PW: International prevalence, recognition, and treatment of cardiovascular risk factors in outpatients with atherothrombosis. JAMA, 2006; 295: 180-189

10) Raven GM: Role of insulin resistance in human disease. Diabetes, 1988; 37: 1595-1607

11) Meigs JB, D’Agostino RBS, Wilson PW, Cupples LA, Nathan DM, Singer DE: Risk variable clustering in the insulin resistance syndrome. The Framingham Offspring Study. Diabetes, 1997; 46: 1594-1600

12) Executive Summary of the Third Report of the National Cholesterol Education Program (NCEP) Expert Panel on Detection, Evaluation, and Treatment of High Blood Cholesterol in Adults (Adult Treatment Pane III). JAMA, 2001; 285: 2486-2497

13) Park YW, Zhu S, Palaniappan L, Heshka S, Carnethon MR, Heymsfield SB: The metabolic syndrome: prevalence and associated risk factor findings in the US population from the Third National Health and Nutrition Examination survey, 1988-1994. Arch Intern Med, 2003; 163: 427436

14) Dixon JB, Dixon ME, O'Brien PE: Alcohol consumption in the severely obese: relationship with the metabolic syndrome. Obes Res, 2002; 10: 245-252

15) Nigam A, Bourassa MG, Fortier A, Guertin MC, Tardif JC: The metabolic syndrome and its components and the long-term risk of death in patients with coronary heart disease. Am Heart J, 2006; 151: 514-521

16) Tillin T, Forouhi NG, McKeigue PM, Chaturvedi N: The role of diabetes and components of the metabolic syndrome in stroke and coronary heart disease mortality in UK white and African-Caribbean populations. Diabetes Care, 2006; 29: 2127-2129

17) Kadota A, Hozawa A, Okamura T, Kadowaki T, Nakmaura K, Murakami Y, Hayakawa T, Kita Y, Okayama Y, Nakamura Y, Ueshima H: Relationship between metabolic risk factor clustering and cardiovascular mortality stratified by high blood glucose and obesity. Diabetes Care, 2007; 30: 1533-1538

18) Okamura T, Tanaka T, Babazono A, Yoshita K, Chiba N, Takebayashi T, Nakagawa H, Yamato H, Miura K, Tamaki J, Kadowaki T, Okayama A, Ueshima H: The high-risk and population strategy for occupational health promotion (HIPOP-OHP) study: study design and cardiovascular risk factors at the baseline survey. J Hum Hypertens, 2004; 18: 475-485

19) Okamura T, Tanaka T, Yoshita K, Chiba N, Takebayashi T, Kikuchi Y, Tamaki J, Tamura U, Minai J, Kadowaki T, Miura K, Nakagawa H, Tanihara S, Okayama A, Ueshima $\mathrm{H}$ : Specific alcoholic beverage and blood pressure in a middle-aged Japanese population: the high-risk and population strategy for occupational health promotion (HIPOP-OHP) study. J Hum Hypertens, 2004; 18: 9-16

20) Naito M, Nakayama T, Okamura T, Miura K, Yanagita M, Fujieda Y, Kinoshita F, Naito Y, Nakagawa H, Tanaka T, Ueshima H: Effect of a 4-year workplace-based physical activity intervention program on the blood lipid profiles of participating employees: the high risk and population strategy for occupational health promotion (HIPOPOHP) study. Atherosclerosis, 2008; 197: 784-790

21) Tamura U, Tanaka T, Okamura T, Kadowaki T, Yamato H, Tanaka H, Nakamura M, Okayama A, Ueshima H, Yamagata Z: Changes in weight, cardiovascular risk factors and estimated risk for coronary heart disease following smoking cessation in Japanese male workers: HIPOPOHP Study. J Atheroscler Thromb, 2010; 17: 12-20

22) Nakamura $M$, Sato $S$, Shimamoto T: Improvement in Japanese clinical laboratory measurements of total cholesterol and HDL-cholesterol by the US Cholesterol Reference Method Laboratory Network. J Atheroscler Thromb, 2003; 10: 145-153

23) Blaha MJ, Blumenthal RS, Brinton EA, Jacobson TA: National Lipid Association Taskforce on Non-HDL Cholesterol. The importance of non-HDL cholesterol reporting in lipid management. J Clin Lipidol, 2008; 2: $267-$ 273

24) Craig CL, Marshall AL, Sjöström M, Bauman AE, Booth ML, Ainsworth BE, Pratt M, Ekelund U, Yngve A, Sallis JF, Oja P: The International Physical Activity Questionnaire (IPAQ): a comprehensive reliability and validity study in twelve countries. Med Sci Sports Exerc, 2003; 35: 1381-1395

25) American Diabetes Association: Diagnosis and classification of diabetes mellitus. Diabetes Care, 2005; 28 Suppl 1: S37-S42

26) Kadota A, Miura K, Okamura T, Hozawa A, Murakami Y, Fujiyoshi A, Takashima N, Hayakawa T, Kita Y, Okayama A, Nakamura Y, Ueshima H; NIPPON DATA90 Research Group: Relationship of moderate metabolic risk factor clustering to cardiovascular disease mortality in non-lean Japanese: a 15-year follow-up of NIPPON DATA90. Atherosclerosis, 2011; 215(1): 209-213

27) Nakamura $Y$, Yamamoto $T$, Okamura $T$, Kadowaki T, Hayakawa T, Kita Y, Saitoh S, Okayama A, Ueshima H: Combined cardiovascular risk factors and outcome: NIPPON DATA80, 1980-94. Circ J, 2006; 70: 960-964

28) Hozawa A, Okamura T, Oki I, Murakami Y, Kadowaki T, Nakamura K, Miyamatsu N, Hayakawa T, Kita Y, Nakamura Y, Nakamura Y, Abbott RD, Okayama A, Ueshima H; NIPPON DATA80 Study Group: Relationship between BMI and all-cause mortality in Japan: NIPPON DATA80. Obesity (Silver Spring), 2008; 16: 1714-1717

29) WHO Expert Consultation: Appropriate body-mass index for Asian populations and its implications for policy and intervention strategies. Lancet, 2004; 363: 157-163

30) Violanti JM, Burchfiel CM, Hartley TA, Mnatsakanova A, Fekedulegn D, Andrew ME, Charles LE, Vila BJ: Atypical work hours and metabolic syndrome among police officers. Arch Environ Occup Health, 2009; 64: 194-201

31) Ghiasvand M, Heshmat R, Golpira R, Haghpanah V, Soleimani A, Shoushtarizadeh P, Tavangar SM, Larijani B: Shift working and risk of lipid disorders: a cross-sectional study. Lipids Health Dis, 2006; 10: 9

32) Jermendy G, Nádas J, Hegyi I, Vasas I, Hidvégi T: Assessment of cardiometabolic risk among shift workers in 
Hungary. Health Qual Life Outcomes, 2012; 10: 18

33) Morikawa $Y$, Nakagawa $H$, Miura K, Soyama Y, Ishizaki M, Kido T, Naruse Y, Suwazono Y, Nogawa K: Shift work and the risk of diabetes mellitus among Japanese male factory workers. Scand J Work Environ Health, 2005; 31: $179-183$

34) Pietroiusti A, Neri A, Somma G, Coppeta L, Iavicoli I, Bergamaschi A, Magrini A: Incidence of metabolic syndrome among night-shift healthcare workers. Occup Environ Med, 2010; 67: 54-57

35) Taylor PJ, Pocock SJ: Mortality of shift and day workers 1956-68. Br J Ind Med, 1972; 29: 201-207

36) Kawachi I, Colditz GA, Stampfer MJ, Willett WC, Manson JE, Speizer FE, Hennekens CH: Prospective study of shift work and risk of coronary heart disease in women. Circulation, 1995; 92: 3178-3182

37) Tuchsen F: Working hours and ischaemic heart disease in Danish men: a 4-year cohort study of hospitalization. Int J Epidemiol, 1993; 22: 215-221

38) Virtanen SV, Notkola V: Socioeconomic inequalities in cardiovascular mortality and the role of work: a register study of Finnish men. Int J Epidemiol, 2002; 31: 614-621

39) Vyas MV, Garg AX, Iansavichus AV, Costella J, Donner A, Laugsand LE, Janszky I, Mrkobrada M, Parraga G, Hackam DG: Shift work and vascular events: systematic review and meta-analysis. BMJ, 2012; 345: e4800

40) Pan A, Schernhammer ES, Sun Q, Hu FB: Rotating night shift work and risk of type 2 diabetes: two prospective cohort studies in women. PLoS Med, 2011; 8: e1001141

41) Lieu SJ, Curhan GC, Schernhammer ES, Forman JP:
Rotating night shift work and disparate hypertension risk in African-Americans. J Hypertens, 2012; 30: 61-66

42) Uetani M, Sakata K, Oishi M, Tanaka K, Nakada S, Nogawa K, Suwazono Y: The influence of being overweight on the relationship between shift work and increased total cholesterol level. Ann Epidemiol, 2011; 21: 327-335

43) Scheer FA, Hilton MF, Mantzoros CS, Shea SA: Adverse metabolic and cardiovascular consequences of circadian misalignment. Proc Natl Acad Sci U S A, 2009; 106: 44534458

44) Wilkinson RT: How fast should the night shift rotate? Ergonomics, 1992; 35: 1425-1446

45) Folkard S: Is there a 'best compromise' shift system? Ergonomics, 1992; 35: 1453-1463

46) Kobayashi T, Suzuki E, Takao S, Doi H: Long working hours and metabolic syndrome among Japanese men: a cross-sectional study. BMC Public Health, 2012; 12: 395

47) Katano S, Nakamura Y, Nakamura A, Murakami Y, Tanaka T, Nakagawa H, Takebayashi T, Yamato H, Okayama A, Miura K, Okamura T, Ueshima H: Relationship among physical activity, smoking, drinking and clustering of the metabolic syndrome diagnostic components. J Atheroscler Thromb, 2010; 17: 644-650

48) Hahn V, Halle M, Schmidt-Trucksäss A, Rathmann W, Meisinger C, Mielck A: Physical activity and the metabolic syndrome in elderly German men and women: results from the population-based KORA survey. Diabetes Care, 2009; 32: 511-513 